\title{
Chapter 19 \\ Effectiveness and Sustainability of Coastal Hybrid Infrastructures for Low-Frequency Large-Scale Disasters: A Case Study of Coastal Disaster Assessment for a Complex Disaster
}

\author{
Ryoichi Yamanaka and Kosuke Nakagawa
}

\begin{abstract}
This study aims to evaluate the functioning of hybrid infrastructures in coastal areas and identify the factors influencing their sustainability. The hybrid infrastructure targeted in this study is in the Osato area in southern Tokushima Prefecture, Japan, and consists of a seashore, coastal embankment, coastal forest, rice paddles, and dune. Numerical analysis and field observations of tsunamis and storm surges were conducted in this study. In the tsunami analysis, the response of the inundation area to the reference water level was evaluated assuming a complex disaster involving a tsunami, storm surge, and sea-level rise. In the storm surge analysis, the mechanism of beach deformation and damage in the coastal forest caused by Typhoon Hagibis (No. 19 in Japan) in 2019 was evaluated, and the historical dune formation process was discussed in this case study. Finally, the design strategy required for hybrid infrastructure is discussed.
\end{abstract}

Keywords Hybrid Infrastructure - Tsunami - Storm surge - Complex disaster · Sea-level rise

\subsection{Current Status and Issues of Coastal Protection Measures in Japan}

Japan has the sixth-longest coastline in the world. The total distance of the coastline is $35,295 \mathrm{~km}$, and approximately $14,500 \mathrm{~km}$ of the coastline requires conservation

R. Yamanaka $(\bowtie)$

Research Center for Management of Disaster and Environment, Tokushima University,

Tokushima, Japan

e-mail: ryoichi_yamanaka@tokushima-u.ac.jp

K. Nakagawa

Kiso Kensetsu Consultant, Co., Ltd, Tokushima, Japan

(C) The Author(s) 2022

F. Nakamura (ed.), Green Infrastructure and Climate Change Adaptation,

Ecological Research Monographs, https://doi.org/10.1007/978-981-16-6791-6_19 
measures. Coastal maintenance was conducted under the Coastal Act. The amendment of the Coastal Act in 1999 expanded the objectives of coastal development to include the environment, usage, and protection. Moreover, measures must cope with the increasing severity of disasters caused by climate change. However, the budget for coastal conservation is decreasing due to the continuing population decline, and the usage pattern of coastal areas is changing. Japan is, therefore, at a stage where new measures are needed for coastal conservation. The Japanese government's efforts to promote green infrastructure and ecosystem-based disaster risk reduction (Eco-DRR) are promoted by these circumstances. Furthermore, the reconstruction of infrastructure is expected to have a synergistic effect on disaster prevention, environmental conservation, and regional development, and it is necessary to clarify how this is to be achieved.

Hybrid infrastructure is considered a realistic strategy for applying green infrastructure to coastal areas. Hybrid infrastructures (Sutton-Grier et al. 2015) combine natural resources and artificial structures that are expected to result in benefits for green infrastructure. An example of a hybrid infrastructure in the coastal zone is a combination of coastal embankments as gray infrastructure and shallow beaches, coastal forests, rice paddies, and dunes as green infrastructure. Existing coastal embankments are designed based on past disaster records and, thus, effectively prevent the past maximum disaster level. In addition, the combination of gray and green infrastructure can be expected to be effective in preventing natural disasters beyond the expected scale. However, the design method of hybrid infrastructures in coastal areas has not yet been established and is still in the research stage; therefore, it is necessary to evaluate their effectiveness and explore management methods from different viewpoints.

A method similar to hybrid infrastructure has been used in the design of coastal protection facilities in Japan. It is called the "Integrated Shore Protection System." It is a method of protecting the coast from storm surges and coastal erosion by combining artificial coastal protection facilities such as levees, artificial beaches, and breakwaters. This system is superior in terms of access to the beach and scenery compared to the method that relies only on massive coastal levees. This system and that of hybrid infrastructure may look similar, but there is a difference in how the community interacts with the infrastructure. Because hybrid infrastructures are included in the category of green infrastructure, hybrid infrastructures also involve maintaining social infrastructure based on the coexistence of people and nature. In other words, hybrid infrastructures are not given unilaterally and managed by the government, like gray infrastructure, but are based on the actions of local people according to their history and intentions. Therefore, to realize hybrid infrastructures, the opinions of stakeholders and an understanding of the origins of the region based on a long-term perspective are indispensable; in other words, it is necessary to design infrastructure according to the characteristics of each region.

Based on the above background, this chapter discusses the effectiveness of hybrid infrastructures against natural disasters that may occur in the future and their maintenance and management measures including their origins and histories. A case study was conducted for a region with a hybrid infrastructure under the risk 
of tsunamis and storm surges. We assume a combined natural disaster caused by a tsunami, storm surge, and sea-level rise due to climate change. The occurrence of such combined disasters is infrequent and has not been a subject of serious discussion. Recently, however, the frequency of flood damage has prompted the Japanese government to approve disaster prevention plans based on maximumexpected levels rather than records. This study was conducted in response to such social demands.

\subsection{Overview of the Study Area}

The coastal area with the hybrid infrastructure targeted in this study is located in the Osato area of southern Tokushima Prefecture, Japan (Fig. 19.1). The Osato area has a semi-arc-shaped natural beach facing the Pacific Ocean, which is called the Osato coast. Behind the beach is a dune, on top of which there is a coastal embankment, pine forest, and village (Fig. 19.2). The length of the coastline is $2457 \mathrm{~m}$, and the

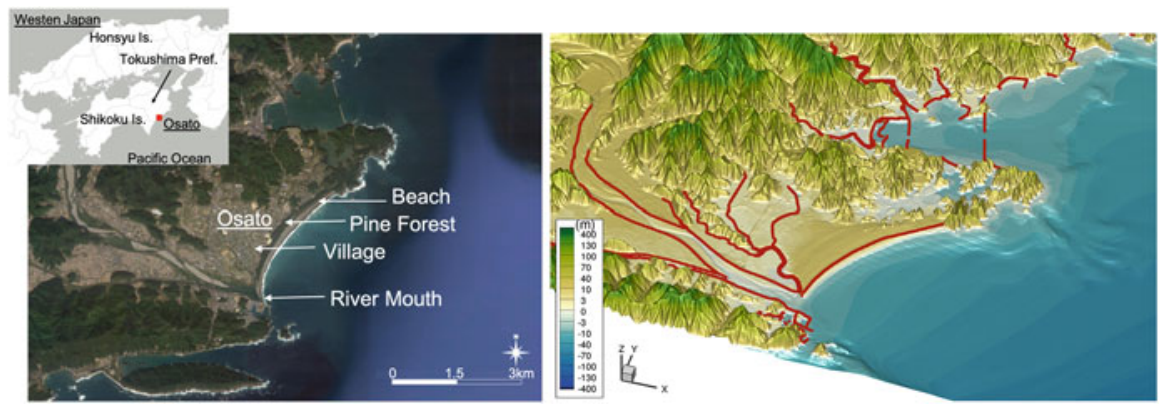

Fig. 19.1 Study area: (left figure) map of the surrounding area of Osato Coast and (right figure) elevation map; red line is the location of the embankment

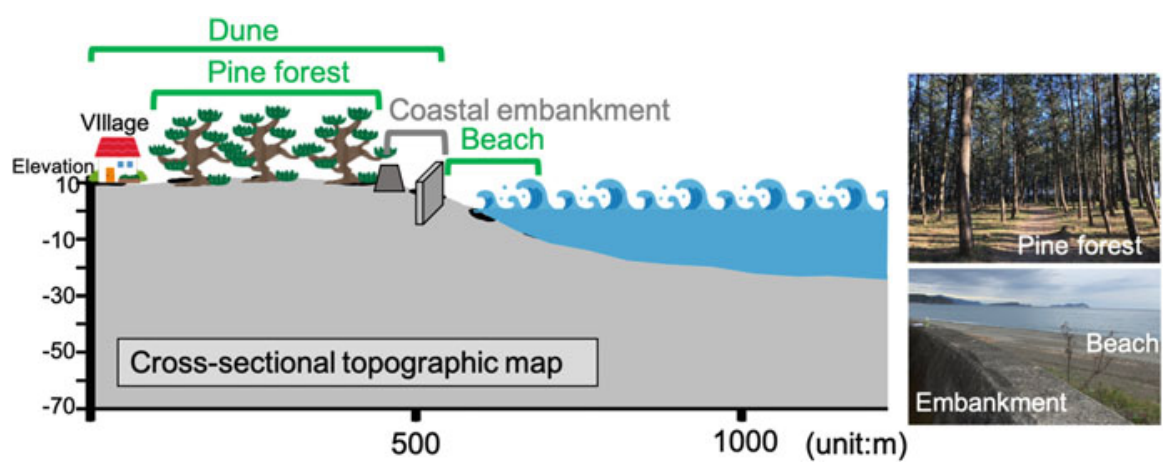

Fig. 19.2 Layout of hybrid infrastructure on the Osato Coast 

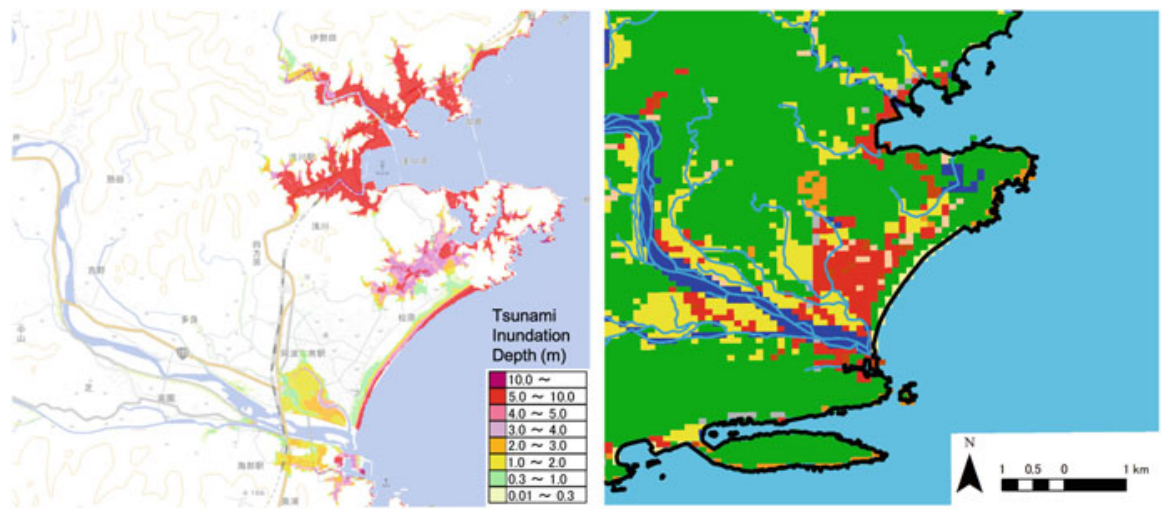

Fig. 19.3 Tsunami hazard map (inundation depth distribution map) published by Tokushima Prefecture (left figure) and land use map taken from the National Land Numerical Information Land Use Subdivision Mesh (right figure). In the right figure, red, yellow, green, blue, and orange indicate the residential area, rice paddies, forests, rivers, and wastelands, respectively

elevation of the dunes is approximately $10 \mathrm{~m}$ above sea level. It faces the Nankai Trough and has experienced periodic Nankai earthquake tsunamis, but there has been no significant damage to the village.

The Great East Japan Earthquake occurred in 2011, and the tsunami damage was more extensive than the prior hazard assessment. After the Great East Japan Earthquake in 2011, the Japanese government revised the hazard assessment of tsunamis originating from the Nankai Trough, which have an identical generation mechanism to the Great East Japan Earthquake. Figure 19.3 shows a tsunami hazard map of the area covered in this study. The Tokushima Prefecture made this hazard map public. This hazard map is for the case of the largest crustal movement estimated by the Japanese government, and the mean water level is set to the mean high tide, which can be regarded as a hazard indicator. Although the tsunami propagated from south to north, the Osato area was not inundated by the tsunami.

Table 19.1 shows the required functions of the hybrid infrastructure on the Osato coast. Beach, pine forest, and dune are examples of green infrastructure, whereas the coastal embankment is an example of gray infrastructure. The functions are divided into three categories, with reference to the Coastal Act: disaster prevention, environment, and regional development. Green infrastructure is expected to serve various functions unlike coastal embankments, which only prevent disaster. However, the performance of some green infrastructure is not easy to quantify. Considering that the evaluation of return on investment is strictly required when designing coastal protection facilities, quantifying these functions is critical. In hybrid infrastructures, where green and gray infrastructures are spatially arranged, the infrastructures may produce synergistic effects.

For example, the tsunami damping effect must be evaluated without dividing these infrastructures because the tsunami gradually dampens as it passes 
Table 19.1 Expected functions of hybrid infrastructure on the Osato Coast

\begin{tabular}{|c|c|c|c|}
\hline & Disaster prevention & Environmental functions & Regional development \\
\hline Beach & $\begin{array}{l}\text { Flood prevention } \\
\text { Landslide prevention }\end{array}$ & $\begin{array}{l}\text { Landscape conservation } \\
\text { Ecosystem conservation } \\
\text { Seawater purification } \\
\text { Biological growth } \\
\mathrm{CO} 2 \text { absorption }\end{array}$ & $\begin{array}{l}\text { Recreation } \\
\text { Amenity improvement } \\
\text { Fishery } \\
\text { Local culture succession }\end{array}$ \\
\hline Embankment & Flood prevention & & \\
\hline Pine forest & $\begin{array}{l}\text { Brown sand prevention } \\
\text { Flying salt prevention } \\
\text { Windstorm protection } \\
\text { Inundation reduction } \\
\text { Space for evacuation }\end{array}$ & $\begin{array}{l}\text { Landscape conservation } \\
\text { Ecosystem conservation }\end{array}$ & $\begin{array}{l}\text { Cultural heritage sites } \\
\text { Place for local activities } \\
\text { Forestry } \\
\text { Tourist destination } \\
\text { Religious sites } \\
\text { Local symbols }\end{array}$ \\
\hline Sand dune & $\begin{array}{l}\text { Brown sand prevention } \\
\text { Flood prevention } \\
\text { Space for evacuation }\end{array}$ & $\begin{array}{l}\text { Landscape conservation } \\
\text { Ecosystem conservation } \\
\text { Water purification } \\
\text { Groundwater recharge }\end{array}$ & $\begin{array}{l}\text { Environmental education } \\
\text { Tourist destination } \\
\text { Water supply }\end{array}$ \\
\hline
\end{tabular}

sequentially through the beach, embankment, and pine forest. For this reason, numerical simulations that can reproduce local conditions are effective, especially for performance related to physical processes.

Another advantage of using numerical simulations to assess the physical damage caused by tsunamis and storm surges is that the assumptions can be easily changed. For example, we can evaluate the effectiveness of the current infrastructure against a typhoon equivalent to the Second Muroto Typhoon (Typhoon 196118, NANCY), which caused extensive damage in the study area. Furthermore, we can predict what would happen if the second Muroto typhoon and the Nankai earthquake tsunami hit simultaneously. As mentioned above, the target area of this study has not been severely damaged by past Nankai earthquake tsunamis. However, if the scale and frequency of natural disasters increase due to climate change, predicting the damage caused by even such low-frequency disasters will provide helpful information for future disaster prevention measures. A possible scenario based on the hybrid infrastructure is that tsunamis and storm surges overtopping coastal levees and embankments will be attenuated by pine forests and dunes behind them, which will act as green infrastructure to prevent them from hitting the village. This study also focuses on the effects of such green infrastructure and draws a hybrid infrastructure function for consideration.

The disadvantage of simulations with virtual external forces is that it is difficult to assess the accuracy of the results. In projections of future climate change effects, multiple scenarios are set up, and policymakers are left to decide which simulation results to adopt. Because numerical simulations evolve as technology advances, policymakers should view the results of simulations as indicative of trends. 


\subsection{Scenario Analysis of Tsunami Hazard by Numerical Simulation}

In the numerical simulation of tsunami hazards, it is necessary to simulate the physical processes from earthquake generation to tsunami propagation. Specifically, we estimated the crustal deformation associated with the earthquake, predicted the sea surface deformation associated with crustal deformation, calculated the tsunami propagation, and predicted the tsunami behavior in the run-up area. In this study, a community model was constructed to simulate physical processes related to tsunamis. JAGURS (Baba et al. 2015, https://github.com/jagurs-admin/ jagurs), a tsunami simulator in a two-dimensional plane and high-performance tsunami calculation code, was used in this study. A two-dimensional model is advantageous because it has high prediction accuracy for long waves with the following characteristics: the horizontal behavior of water particles in the water does not depend on the water depth, and the velocity at the water surface and the bottom are almost the same. The tsunami calculation code is a community model that can handle nonlinear dispersive waves, developed in collaboration with the Japan Agency for Marine-Earth Science and Technology, the Meteorological Research Institute, and the Australian National University. JAGURS implements a nested algorithm to increase the resolution of specific regions and has a multi-scenario execution capability. JAGURS is based on a differential method using a staggered grid and the Leapfrog method and can be used in spherical or Cartesian coordinate systems. The code is written in Fotran90 and can be used for parallel and large-scale computations using OpenMP and MPI.

The semi-infinite homogeneous elastic body model (Okada 1985) was used to calculate the crustal movement in the fault model. The spatial distribution of crustal deformation can be obtained by assigning the reference position of the fault, depth from the surface, length of the fault, fault width, dip angle, strike angle, slip angle, and slip rate of the fault. Then, based on the distribution of crustal deformation, the elevation distribution can be modified, and sea-level deformation can be set.

The fault model used in this study was proposed by the Nankai Trough Mega Earthquake Model Study Group of the Cabinet Office of the Japanese government. In this study, we adopted scenario No. 3 , in which a large slip zone is located in the south of the study area. Figure 19.4 shows the spatial distribution of the crustal movement. The maximum uplift is approximately $8 \mathrm{~m}$ in the southern part of the study area (top figure of Fig. 19.4), while the subsidence of 0.65 to $0.9 \mathrm{~m}$ was calculated in the target area (bottom figure of Fig. 19.4). In the target area, such a decrease in elevation over a wide area increases tsunami damage.

The topography for the numerical simulation was set up by combining different spatial resolutions for each area. This method is called "nesting," and it can improve computational efficiency. Figure 19.5 shows the mesh layout used in this study. Five mesh sizes ranged from 10 to $810 \mathrm{~m}$. The influence of the geomaterials on the surface flow was expressed using Manning's roughness coefficient. Figure 19.6 shows the distribution of the roughness coefficients. 

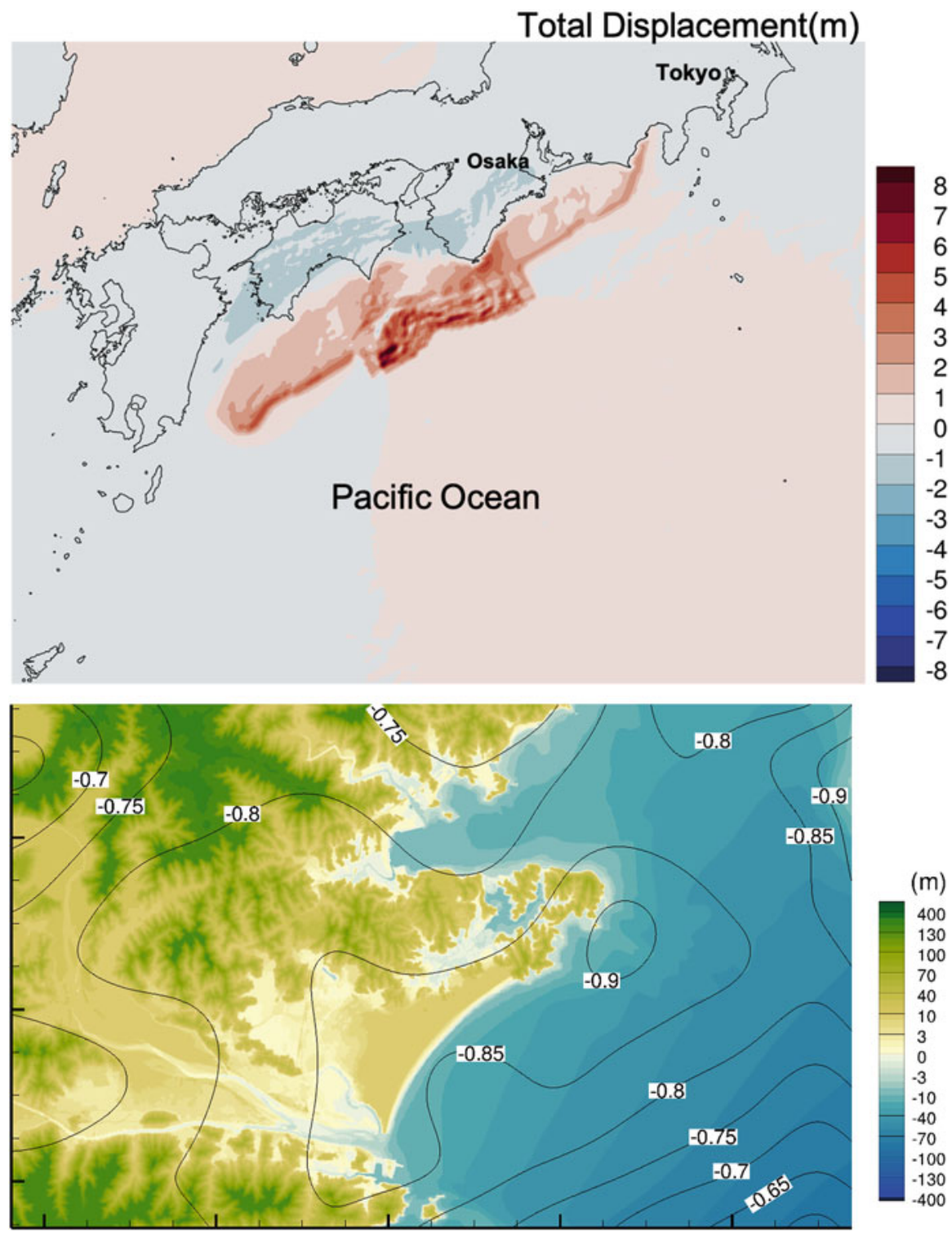

Fig. 19.4 Fault displacement distribution used for input (top figure) and magnified view in the area to be analyzed (bottom figure, coloring indicates elevation, contour lines indicate fault displacement distribution)

The scenarios assumed in this study are listed in Table 19.2. In all scenarios, the tsunami was input by the fault model described above, and the mean sea level varied for each scenario. In Case 1, as shown in Table 19.2, we set the mean high tide level 


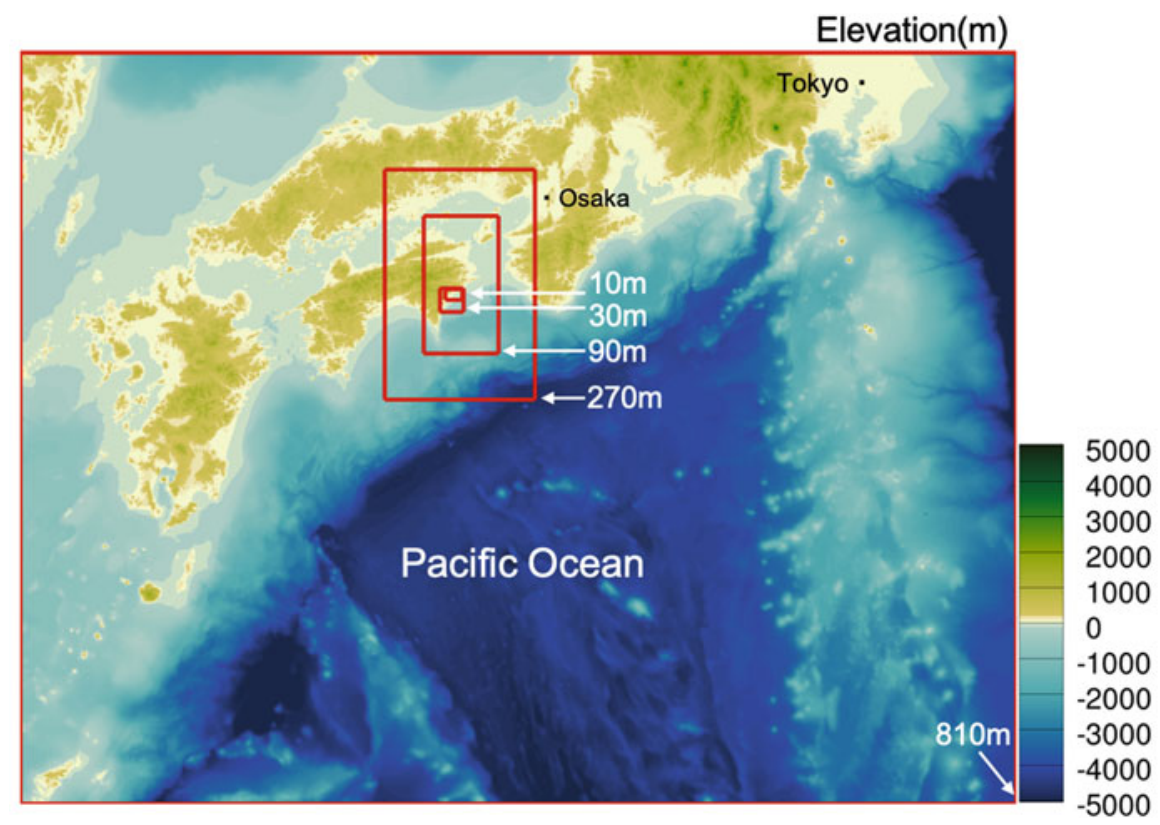

Fig. 19.5 Arrangement of computational grids and computational grids spacing (coloring indicates elevation)

as the mean water level. In Case 2, a typhoon of the same level as the second Muroto typhoon was assumed, and the sea level rise was set based on the records. In Case 3, we assumed that a typhoon larger than the Second Muroto Typhoon strikes with the same level of pressure and wind as the Isewan Typhoon (Typhoon 195915, VERA) and set the sea-level rise using storm surge predictions for Tokushima Prefecture. In Case 4, the IPCC (AR5, WG1) projections were used for sea-level rise, and in this case, the sea-level rise was set for the most severe warming between 2081 and 2100 (RCP8.5) in Case 2. In Case 5, we set the IPCC projection of sea-level rise in the case of the most severe warming (RCP8.5) in Case 3. Although it is difficult to estimate the probability of each scenario, the probability of periodic Nankai earthquake tsunamis is not considered here because it varies depending on when it is estimated. However, in this study, we interviewed experts in coastal engineering and obtained rough estimates of the probability of water level change, as shown in Table 19.2.

Figure 19.7 shows the results of the tsunami inundation simulations calculated based on the scenarios. The results are overlaid with satellite images and inundation depths with the indicated colors. The hazard map provided by the Tokushima Prefecture is also shown for comparison. The tsunami propagated from the south of the coast and moved to hit the coast and mouth of the river, then ran up to the land by flooding the coast or up the river. We compared the hazard maps and Case 1 in the inundation areas. The inundation areas were the same, but in the pine forests 


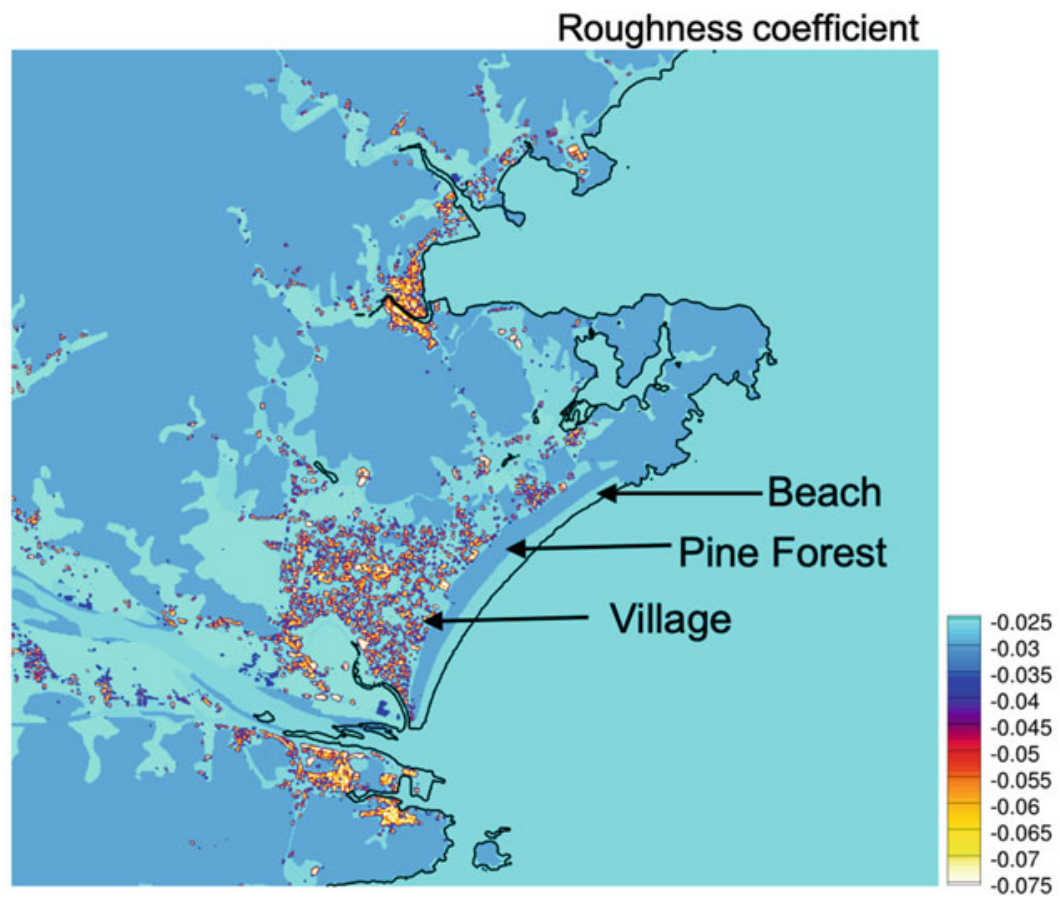

Fig. 19.6 Spatial distribution of roughness coefficients (negative values are due to model limitations, but are actually positive values)

Table 19.2 List of scenarios assumed in this study. The external tsunami force is the same for all scenarios, and only the reference water level is changed for each scenario

\begin{tabular}{l|l|l|l}
\hline & Scenario assumptions & Mean sea level & $\begin{array}{l}\text { Estimated probability of } \\
\text { water level occurrence }\end{array}$ \\
\hline Case1 & Mean sea level of spring tide & T.P. $+0.92 \mathrm{~m}$ & Once a month \\
\hline Case2 & $\begin{array}{l}\text { Storm surge at the level of the second } \\
\text { Muroto typhoon }\end{array}$ & T.P. $+2.85 \mathrm{~m}$ & 50 years \\
\hline Case 3 & $\begin{array}{l}\text { A typhoon with the same pressure as } \\
\text { the second Muroto typhoon and the } \\
\text { same wind level as the Isewan typhoon }\end{array}$ & T.P. $+3.60 \mathrm{~m}$ & 100 years \\
\hline Case 4 & $\begin{array}{l}\text { Case 2 and the highest predicted } \\
\text { average global mean sea level for } \\
\text { 2081-2100 by IPCC (AR5 WG1) }\end{array}$ & T.P. $+3.67 \mathrm{~m}$ & 150 years \\
\hline Case 5 & $\begin{array}{l}\text { Case 3 and the highest predicted } \\
\text { average global mean sea level for } \\
\text { 2081-2100 by IPCC (AR5 WG1) }\end{array}$ & T.P. $+4.42 \mathrm{~m}$ & 200 years \\
\hline
\end{tabular}

T.P. means Tokyo Peil 

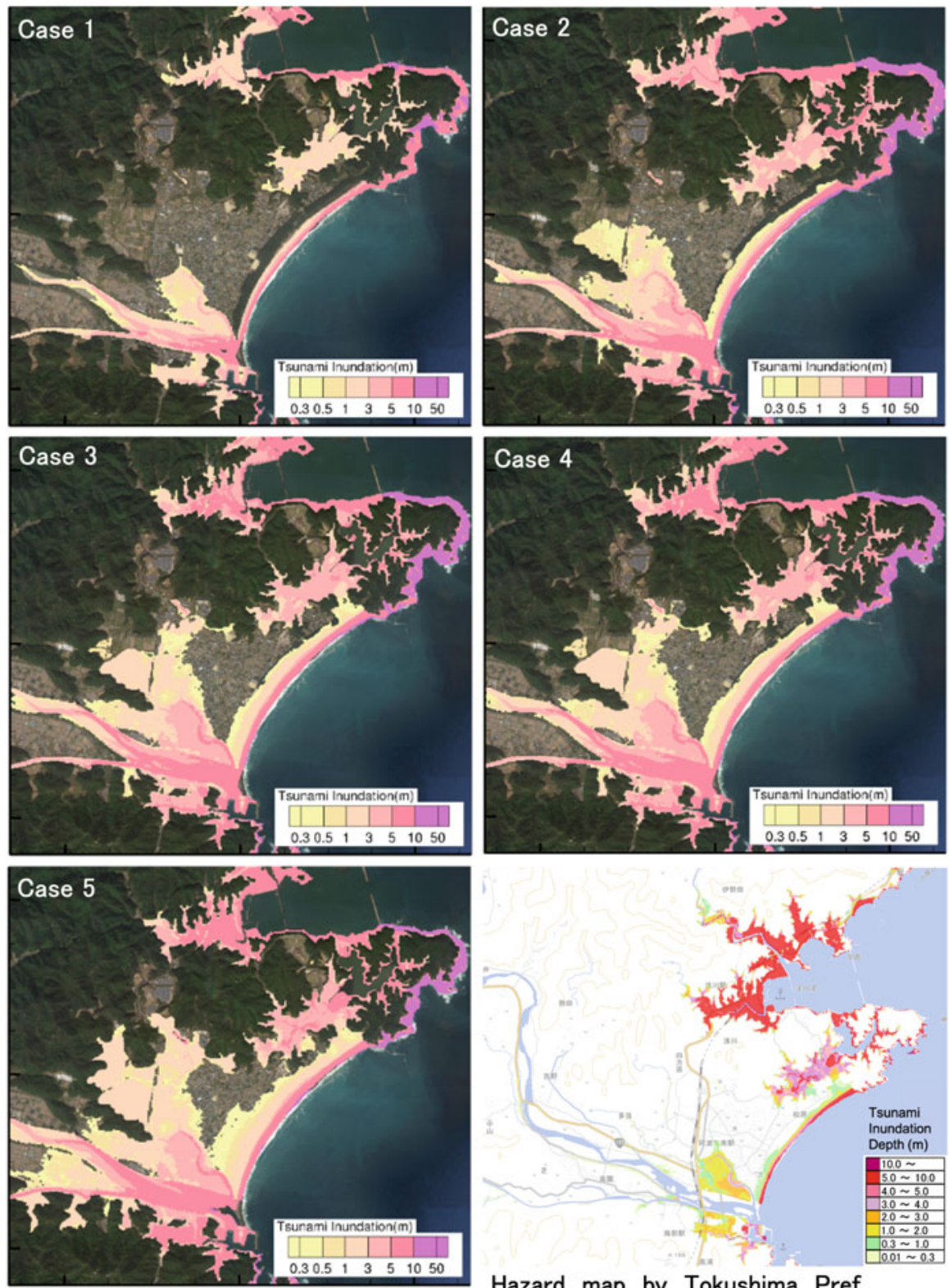

Hazard map by Tokushima Pref., (same condition as Case1)

Fig. 19.7 Distribution of inundation depths for each scenario calculated by numerical analysis and hazard map of inundation depth by Tokushima Prefecture 
behind Osato Beach, the latter was more extensive near both ends of the beach. This is because the hazard map is a superposition of the maximum values obtained from tsunami inundation simulations using multiple fault models, which is different from the method used in this study. Therefore, the fault model in this study was considered appropriate for hazard assessment.

Next, we focused on a tsunami that ran from the beach to the pine forest. In Cases 1 and 2, the tsunami did not spread to the pine forest. However, in Cases 3 and 4, the tsunami inundation area extended to the entire pine forest area over the coastal embankment. In Case 5, the tsunami inundation area extended beyond the pine forest to the residential area. Similarly, when comparing the inundation areas spreading from the river mouth to the northwest, the inundation area in each case is different, and when the sea level rises, most of the area located behind residential areas will be inundated. Because rice paddies in the locations highlighted in yellow in the right figure of Fig. 19.3 are in the inundation area, the waterlogging effect of rice paddies was also included in the elevation distribution in this study. The above results can be summarized as follows. In Cases 1 and 2, the tsunami inundation was limited by coastal and river levees, and the scale of the external force was sufficient for the gray infrastructure to be effective. In Case 5, the tsunami reached the residential area beyond both gray and green infrastructures.

Figure 19.8 shows that the inundation area increases nonlinearly as the initial water level increases. Here, we consider the infrastructures that mainly contributed to reducing inundation in each scenario: Cases 1 and 2 can be regarded as the result of using gray infrastructures (coastal levees and river levees). Cases 3-5 are the result of using green infrastructure (dunes, pine forests, and rice paddies). The results imply that the effect of green infrastructure decreases nonlinearly as the external force increases. This is because not all levees break at once, and levees are installed in multiple layers at the water's edge and land.

The effects of gray and green infrastructure are interactive phenomena, and it is not easy to separate and discuss their physical disaster prevention effects. Understanding the effects of infrastructure holistically by changing the scale of external forces is important. It is possible to calculate the benefits of changing the conditions of infrastructure, such as the height of coastal embankments and vegetation density in pine forests, based on the assets in the flooded area. However, it should be noted that the assets in the flooded area cannot be fully expressed by only considering fixed assets such as houses and government facilities. It is essential to clarify what assets are needed to safeguard local peoples' lives and consider measures to increase infrastructure effectiveness. 


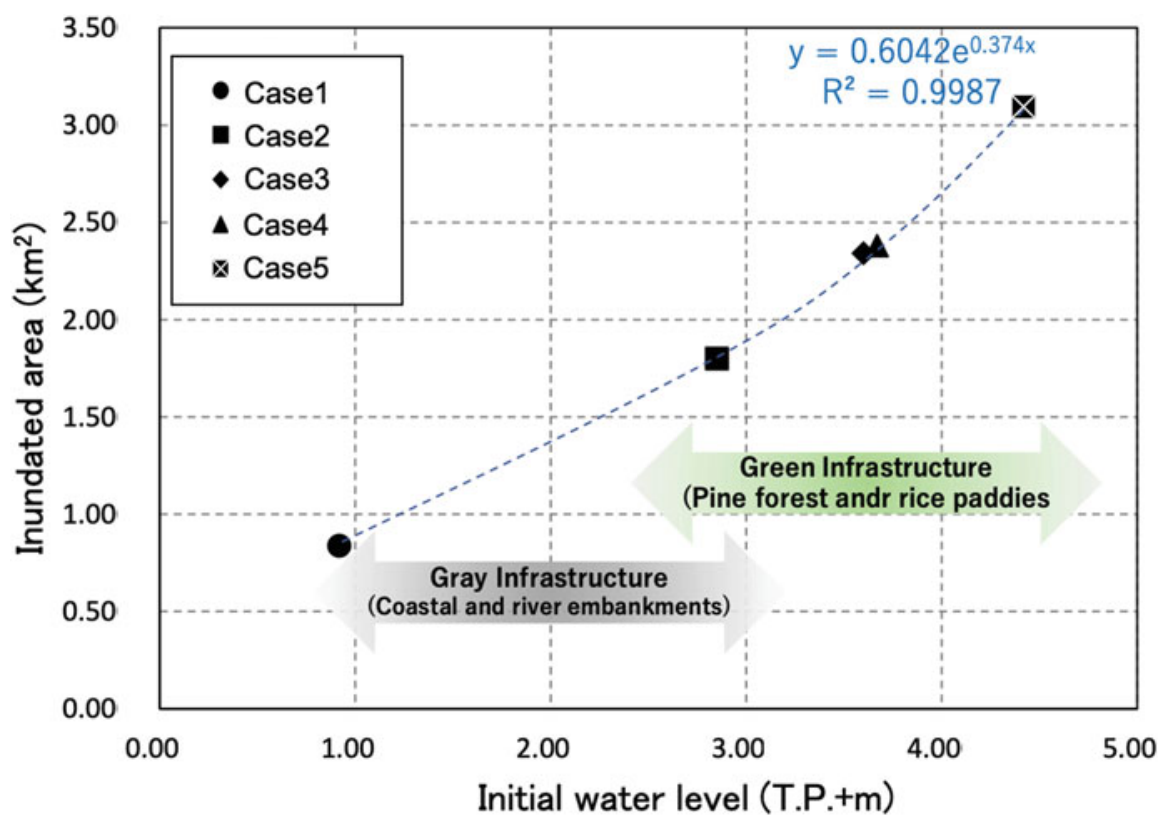

Fig. 19.8 Relationship between initial average water level and flooded area

\subsection{Relationship Between Typhoons and the Formation Process of Hybrid Infrastructure}

Typhoon 201919 (HAGIBIS) occurred in the Pacific Ocean on October 5, 2019. It gradually turned northward, approached the Tokai and Kanto regions of Japan from October 12 to 13, and disappeared east of the Kamchatka Peninsula on October 14. The pressure at the time of the approach was $945 \mathrm{hPa}$, and the maximum radius of the storm area was $370 \mathrm{~km}$. The typhoon reached the Japanese archipelago with a very strong force, causing severe damage in western and eastern Japan. Although Shikoku Island, the target area in this study, was far from the typhoon's path, it caused severe damage to the Osato coast.

Figure 19.9 shows a summary of the information on typhoon-induced waves recorded at nearby observation sites. The blue squares show the significant wave height and the significant wave period at the time of the maximum wave height, and the yellow triangles show the significant wave period and the significant wave height during the maximum wave period. The solid and dashed lines represent the waveform gradient; the closer it is to the solid line, the larger is the swell size. The points in the red circle are the values for this typhoon, indicating that the swell reached its highest level in terms of both wavelength and period. This figure is based on the statistical results of the past 50 years. This means that the probability of the swell generated by this typhoon was more than 50 years. 


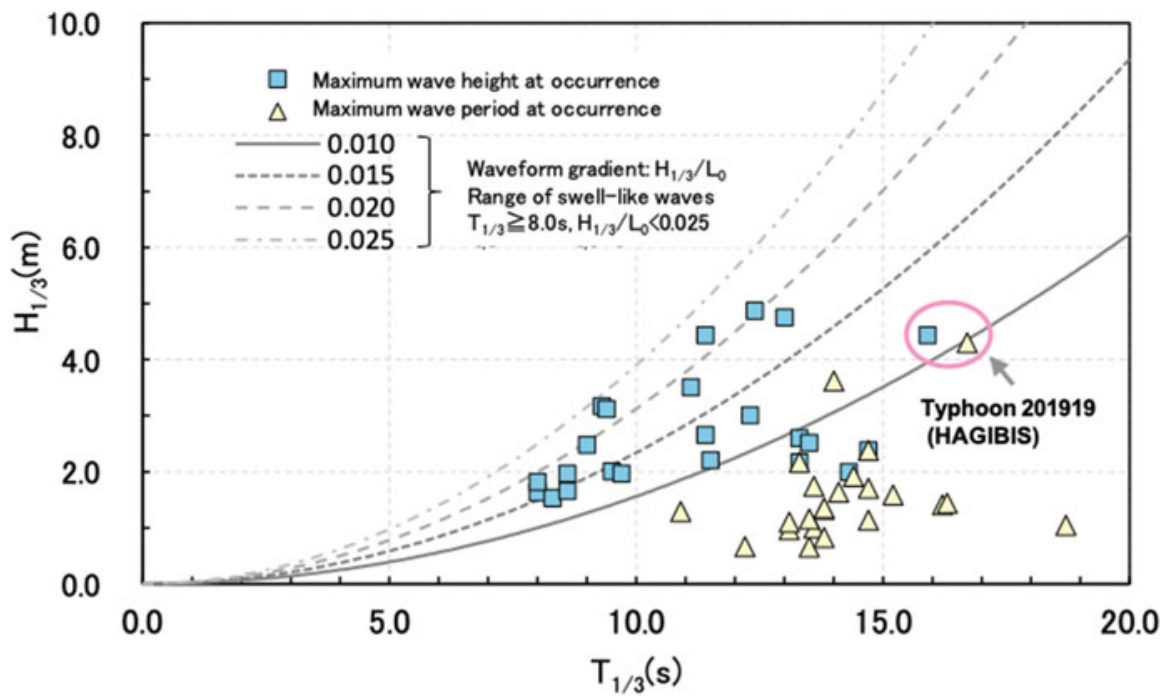

Fig. 19.9 Record of waves during past typhoons at the nearest observatory to the Osato Coast. The $\mathrm{x}$-axis represents the significant wave period, and the y-axis represents the significant wave height
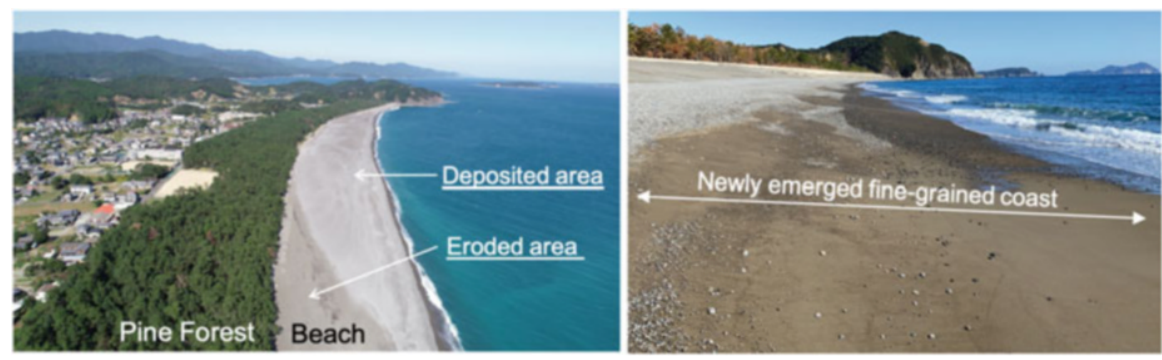

Photo 19.1 Aerial photo by drone (taken from the south side of the beach facing north, October $16,2019)$ and a photo of the beach center near the shoreline

Photo 19.1 depicts a beach scene on October 16, 2019, 3 days after the typhoon passed. Beach deformation occurred even in the upper tidal zone, as well as largescale sand movement. In addition, near the coastline in the center of the beach, fine sandy soil newly formed, which was not present before the passage of the typhoon. The gravel that was present before the typhoon hit was pushed out to the pine forest behind, and gravel and seawater invaded the pine forest. Such large-scale beach deformation has not been recorded in recent years. However, an 80-year-old local woman said that the beach returned to its shape when she was a child. This suggests that this type of beach deformation has occurred in the past.

Figure 19.10 shows the distribution of the change in ground height caused by the typhoon based on the observed data. This figure shows that the ground height 


\section{Amount of change in ground surface height $(\mathrm{m})$}

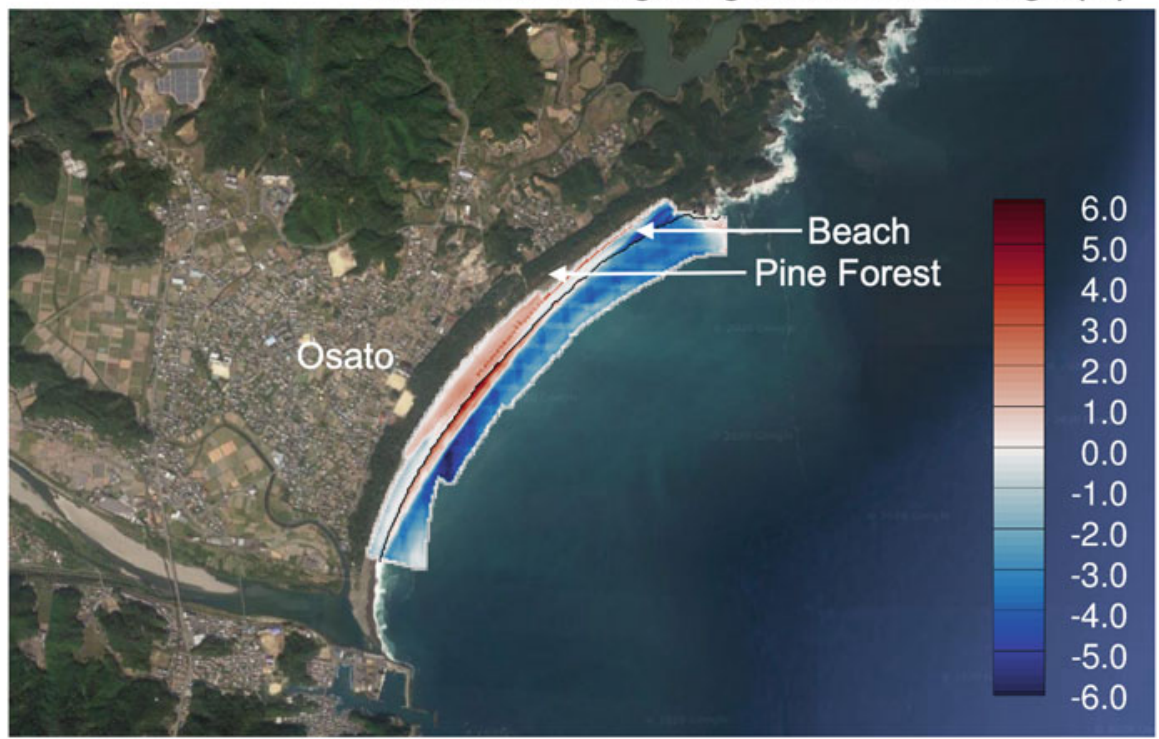

Fig. 19.10 Distribution map of the difference in ground elevation before and after the typhoon. Positive values indicate sedimentation, and negative values indicate erosion

increased at the beach center and decreased at both ends. According to published boring data (Tokushima Prefecture), the bottom sediment of the Osato Coast is sandy below the sea surface, whereas gravel spreads in the tidal zone, suggesting that the sandy ground seen in Photo 19.1 was formed because of the movement of sand from the seaside to the landside. The occurrence of beach deformation caused by the typhoon suggested the origin of the dune, which is a high ground where pine forests and villages are located. The mouth of the Kaifu River is located at the southern end of the Osato coast, which supplies sand to the sea area when the river flows out after heavy rains. Fine sand supplied by the river exists on the seabed of the Osato coast, but under normal wave conditions, this sand accumulates rather than moves. However, typhoons with billows pass through the area about once every 50 years, causing large-scale beach deformation, such as that seen here. As a result, sea sand was lifted inland, and dunes were formed over a long period. This means that the dune behind the hybrid infrastructure in the Osato area has a mechanism to enhance its disaster prevention function through natural processes.

After this large-scale beach deformation, residents raised the issue of seawater inundation into the pine forest, which prompted the government to conduct restoration work on beach deformation by moving the sand in the tidal zone offshore, but the same phenomenon is expected to occur if a similar typhoon passes through again. Therefore, this construction work is considered a countermeasure against high waves that occur frequently. Figure 19.11 shows the run-up area due to high 

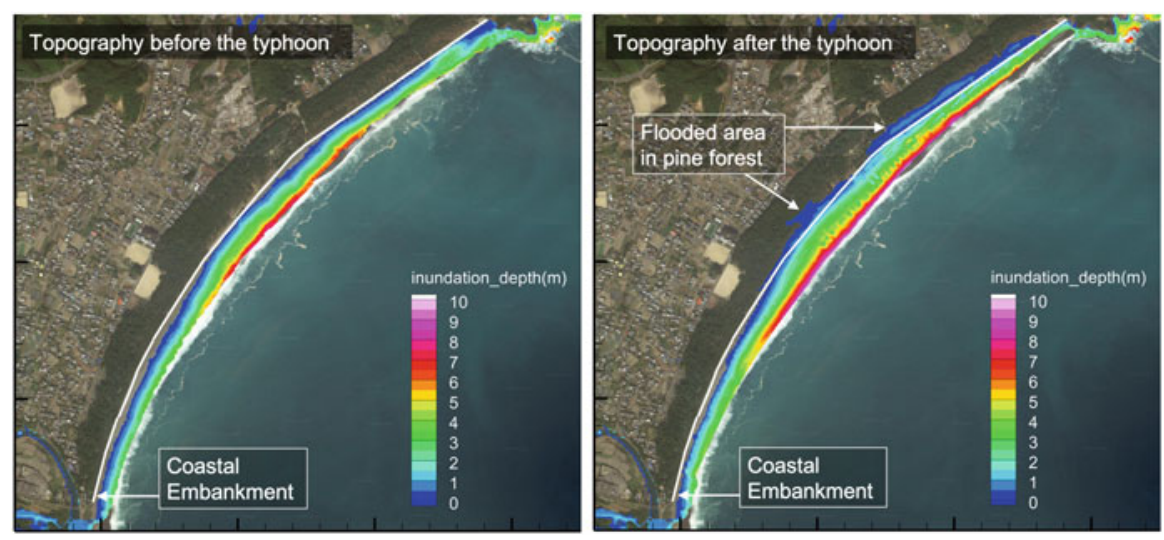

Fig. 19.11 Inundation area by high waves calculated by the wave model (comparison of different terrains applied)

waves calculated using the wave analysis model "Celeris" (Tavakkol and Lynett 2017). Celeris is a numerical wave analysis model based on the extended Boussinesq equations. A hybrid finite volume method was used to discretize the fundamental equations. In this study, boundary conditions based on the JONSWAP spectra were set up to reproduce the wave conditions during the typhoon. The directional function is assumed to follow the Mitsuyasu equation (Mitsuyasu et al. 1975). The boundary conditions of the wave spectra were obtained from the results of wide-area calculations based on the energy equilibrium equation, and the parameters at the boundary of the calculation domain were input. Three hundred wave inputs for the topography before and after the typhoon passage were used. When the topography before the typhoon was applied, the waves did not reach the pine forest area. In contrast, when the topography after the typhoon was applied, the waves reached the pine forest area. The white line in the figure is the boundary between the beach and pine forest, where the coastal embankment is located. In reality, beach deformation occurred in tandem with typhoons. However, as the beach deformation progressed, the situation changed, such that the waves could efficiently run up to the higher elevation pine forest area. This indicates that it is difficult to control seawater intrusion into the pine forest under the same scale of external force as the typhoon.

Knowing the origin of the natural environment in green infrastructure suggests how hybrid infrastructure can be maintained. Figure 19.12 shows a conceptual diagram of the effect of coastal embankments on the natural dune formation process. From this figure, to enhance the dunes as green infrastructure, it is better if there is no dike at the current location (bottom figure). However, if there is no embankment at the current location, preventing seawater from flooding the pine forest will be a challenge. Although this is not shown in detail here, many pine trees died due to seawater inflow during this time. This indicates the loss of ecosystem services provided by the pine forests. Thus, changing the position of the embankment causes a trade-off in ecosystem services. Such trade-offs of 


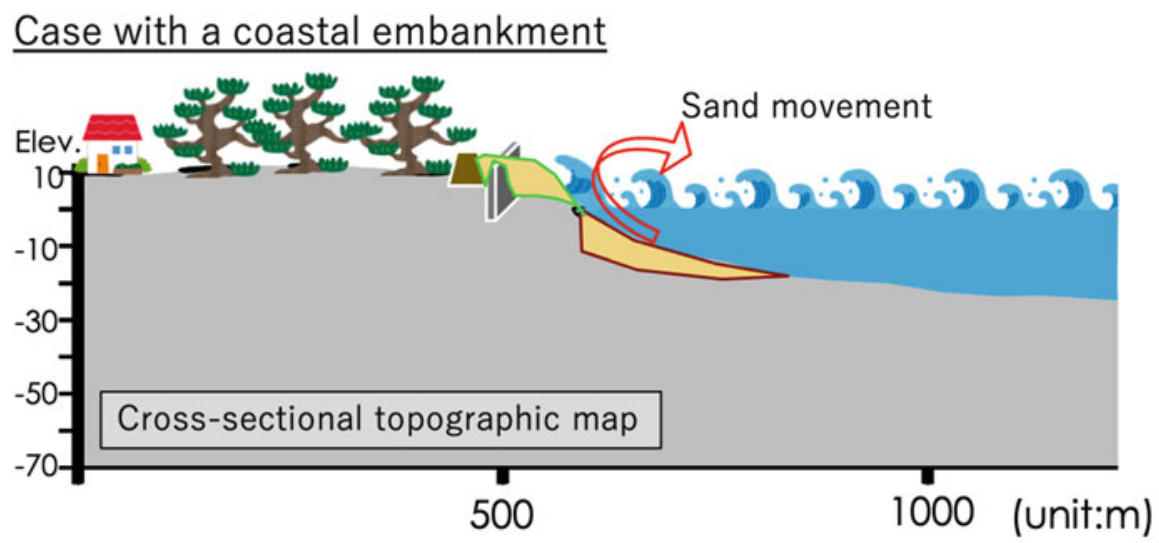

\section{Case without coastal embankment}

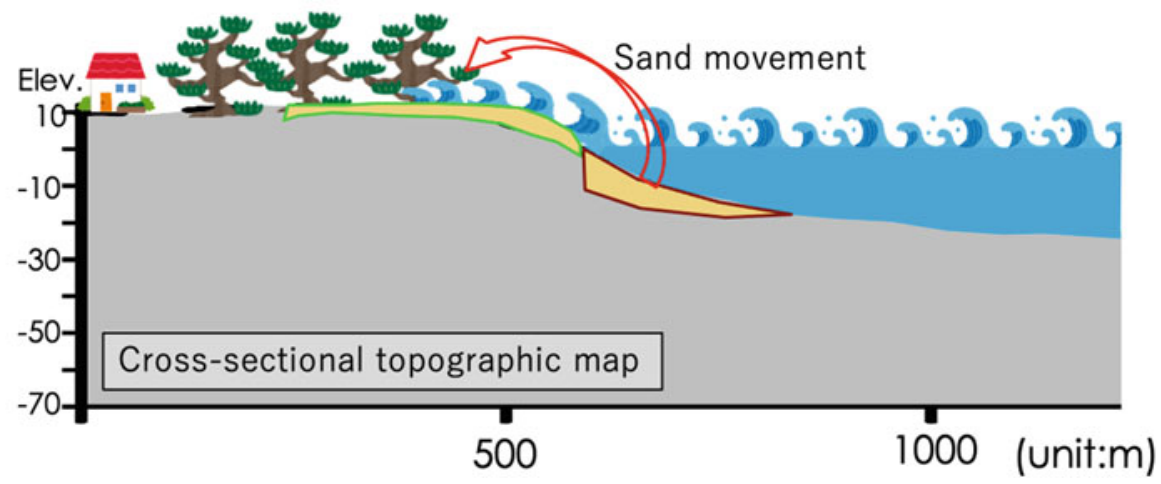

Fig. 19.12 Relationship between coastal embankments and sand movement due to meteorological events in hybrid infrastructure

ecosystem services brought by hybrid infrastructure should be considered during design. Even though various options have been proposed, residents' opinions are essential. In the Osato area, pine forests are essential for the sustainability of the community, and avoiding the loss of pine forests is the most important consideration. This area modified the coastal topography to increase the effectiveness of the coastal embankment, which is the gray infrastructure in the hybrid infrastructure. Waiting for nature to raise the elevation of the dunes and prevent the waves from inundating the pine forest is impractical. In other words, the time required for the formation of green infrastructure is another factor behind this choice. When designing hybrid infrastructures, it is also essential to understand how the functions of green infrastructure change over time.

Acknowledgments We sincerely thank Mr. Tadashi Saito for his assistance. We are grateful to Dr. Fumika Asanami, Prof. Yasunori Muto, Prof. Mahito Kamada, Prof. Futoshi Nakamura, Dr. Hajime Matsushima, and Dr. Yota Imai for helpful discussions. This research was performed 
by the Environment Research and Technology Development Fund (JPMEERF20184005) of the Environmental Restoration and Conservation Agency of Japan. This study was also supported by a Grant-in-Aid from the Ministry of Education, Science, Technology, and Sports of Japan (18K04659). Topographic data for tsunami analysis were provided by the Tokushima Prefecture and West Nippon Expressway Company Limited.

\section{References}

Baba T, Takahashi N, Kaneda Y, Ando K, Matsuoka D, Kato T (2015) Parallel implementation of dispersive tsunami wave modeling with a nesting algorithm for the 2011 Tohoku tsunami. Pure Appl Geophys 172:3455-3472

Mitsuyasu H, Tasai F, Suhara T, Mizuno S, Ohkusu M, Honda T, Rikiishi K (1975) Observation of the directional spectrum of ocean waves using a cloverleaf buoy. J Physical Oceanogr 5(4):750 760

Okada Y (1985) Surface deformation due to shear and tensile faults in a half-space. Bull Seismol Soc Am 75(4):1135-1154

Sutton-Grier AE, Wowk K, Bamford H (2015) Future of our coasts: the potential for natural and hybrid infrastructure to enhance the resilience of our coastal communities, economies and ecosystems. Environ Sci Pol 51:137-148

Tavakkol S, Lynett P (2017) Celeris: a GPU-accelerated open source software with a Boussinesqtype wave solver for real-time interactive simulation and visualization. Comput Phys Commun 217:117-127

Tokushima Prefecture: Awajiban. https://e-awajiban.pref.tokushima.lg.jp (in Japanese)

Open Access This chapter is licensed under the terms of the Creative Commons Attribution 4.0 International License (http://creativecommons.org/licenses/by/4.0/), which permits use, sharing, adaptation, distribution and reproduction in any medium or format, as long as you give appropriate credit to the original author(s) and the source, provide a link to the Creative Commons license and indicate if changes were made.

The images or other third party material in this chapter are included in the chapter's Creative Commons license, unless indicated otherwise in a credit line to the material. If material is not included in the chapter's Creative Commons license and your intended use is not permitted by statutory regulation or exceeds the permitted use, you will need to obtain permission directly from the copyright holder. 